\section{Imagery and learning in deaf and hearing children*}

\section{JAMES C. MacDOUGALL† and M. S. RABINOVITCH \\ McGill University, Montreal, P.Q. Canada}

An experiment was conducted to determine the role of auditory and kinesthetic cues produced by overt verbalizations in a learning situation. Two groups of deaf and one group of hearing children were required to learn three paired-associate lists consisting of pictures, words, and nonsense syllables. One deaf group and the hearing group used speech in the verbalization condition, while the remaining deaf group used signing and fingerspelling as a method of verbalization. The results indicated that overt verbalizations did not lead to an improvement in performance for any of the groups in any of the conditions. The relative importance of auditory and kinesthetic imagery in the process of recall and recognition was discussed, and suggestions were made concerning the relevance of these findings for linguistic development in deaf children.

A number of experiments have indicated that the deaf do not perform as well as the hearing in various visual memory and learning situations (Pintner \& Paterson, 1916, 1917; Blair, 1957; Hartman \& Elliott, 1965). Pintner \& Paterson (1916, 1917) suggested that the inability of deaf Ss to engage in verbalizations and thereby provide themselves with auditory imagery accounted for this deficit. This hypothesis is consistent with the finding that hearing Ss depend on an auditory system of coding visual information (Conrad, 1962, 1964. Sperling, 1963), while deaf Ss do not (Conrad \& Rush, 1965). If auditory imagery is necessary for optimal performance in this situation, then it would appear that the deaf have no opportunity to improve their performance. However, the recent experiments of Wickelgren (1965, 1969) and Hintzman (1965) with normal Ss have raised the possibility that imagery in yet another modality-the kinesthetic-can be effective in visual memory. This suggests that if the deaf make maximum use of all the kinesthetic cues which are available to them, then any disadvantage which might attach to the inability to utilize an auditory coding system might be overcome.

in the present experiment, an attempt was made to provide deaf Ss with more visual and kinesthetic cues than they would normally receive in a verbal learning situation. This was accomplished by having the Ss rehearse overtly during learn.. o. It was possible to have rehearsal in two different modalities, since two deaf

\footnotetext{
* This work is based on a thesis submitted by the senior author to the Faculty of Graduate Studies, McGill University, in partial fulfillment for the $M A$ degree.

fNow at the Institute for Research in Human Abilities, Memorial University, St. John's, Newfoundland. Canada.
}

groups who used different methods of communication were studied. One deaf group, who used the "oral" method of communication, was instructed to rehearse by attempting to speak so that they would receive the kinesthetic feedback provided by the speech mechanisms, and in addition, they would receive minimal auditory feedback, depending on the extent of their residual hearing.

A second deaf group, who used the "manual" method of communication, were instructed to "sign" or fingerspell during learning so that they could capitalize on the kinesthetic and visual feedback which this activity would provide. The hearing control group was instructed to rehearse out loud during learning.

The basic rationale was that the overt rehearsal in these various modalities, especially in the case of the deaf groups, would provide sensory cues in a modality which could form the basis of a coding or memory system for visually presented material. It is possible that if the visual and kinesthetic modalities are emphasized for deaf Ss, then their performance in the important skills associated with verbal learning could be improved significantly.

A further objective of the study was to determine if there was a differential effect of overt verbalization in these modalities for different types of stimulus materials. In the present study the Ss were required to learn pictures, words, and nonsense syllables. The pictures were chosen because the deaf presumably can deal with this type of material as well as, or better than, hearing Ss (Mykelbust, 1960 ). Words were used because it is the deficit on the part of deaf Ss to deal with verbal material that is of primary concern. And, finally, the nonsense syllables were used because they represent a type of stimulus that is novel to both deaf and hearing Ss, and what is more important, the problem of differential experience with the meaning of words between deaf and hearing Ss is controlled.

\section{SUBJECTS}

Three groups of Ss were tested. The first group consisted of 12 deaf children who use manual sign language as a method of communication. The second group consisted of 14 deaf children who use speech as a method of communication. The third group consisted of 19 children with normal speech and hearing. The sex, age, grade, intelligence, and hearing status of each group is summarized in Table 1. The intelligence of the normal group was assessed by teachers' ratings and by scores on the Henmon-Nelson IQ test (1932). The mean IQ score was 112 , with a range of $104-117$. The intelligence of the deaf-oral group was assessed by teachers' ratings on a 5-point scale (A-E) in regular use at their school, and no $S$ was included whose rating was lower than a " $C$ " or higher than a "B." Finally, the intelligence of the deaf-manual group was assessed by teachers' ratings on a 3-point scale used at their school, and only those children rated as "average" were included in the group.

\section{TEST MATERIALS}

Two sets of equivalent lists were used in this experiment. Each set contained a list of pictures, a list of words, and a list of nonsense syllables. The pictures were selected from a Grade 1 reader, the words were selected from the Thorndike-Lorge list

Table 1

Age, Grade, Intelligence, Hearing Status, and Sex of Deaf-Oral, Deaf-Manual, and Normal Groups

Deaf-Oral Deaf-Manual Normal

$\begin{array}{lll}(N=14) & (N=12) & (N=19)\end{array}$

\begin{tabular}{llll} 
Mean Age & 12 Years 5 Months & 14 Years 1 Month & 11 Years 0 Months \\
Age Range & $8-8$ to $15-6$ & $9-10$ to $18-0$ & $8-9$ to $13-3$ \\
Grade Range & III to VII & III to VII & III to VI \\
Intelligence Rating & Average & Average & Average \\
Hearing Status & +85 dB Loss & +85 dB Loss & Normal \\
Sex & 7 Male, 7 Female & 6 Male, 6 Female & 10 Male, 9 Female \\
\hline
\end{tabular}


Table 2

Paired-Associate Learning Scores for Deaf and Hearing Groups

\begin{tabular}{|c|c|c|c|c|c|c|c|c|}
\hline & \multicolumn{4}{|c|}{ Verbalization } & \multicolumn{4}{|c|}{ Nonverbalization } \\
\hline & Hearing & $\begin{array}{c}\text { Deaf- } \\
\text { Oral }\end{array}$ & $\begin{array}{c}\text { Deaf- } \\
\text { Manual }\end{array}$ & Mean & Hearing & $\begin{array}{l}\text { Deaf- } \\
\text { Oral }\end{array}$ & $\begin{array}{c}\text { Deaf- } \\
\text { Manual }\end{array}$ & Mean \\
\hline Pictures & 2.78 & 2.71 & 2.75 & 2.74 & 3.10 & 2.78 & 2.50 & 2.79 \\
\hline Words & 5.78 & 5.28 & 6.08 & 5.71 & 7.68 & 6.14 & 7.66 & 7.16 \\
\hline Syllables & 8.05 & 7.92 & 9.83 & 8.60 & 6.36 & 8.07 & 11.75 & 8.72 \\
\hline Mean & 5.53 & 5.30 & 6.22 & 5.88 & 5.71 & 5.66 & 7.30 & 6.22 \\
\hline
\end{tabular}

Note-Scores represent mean number of trials to criterion.

(1944) of the 500 most frequent words, and the syllables were chosen from Noble's list (1961) of CVC trigrams which had an $m^{\prime}$ value of 1.80-1.93. Each list contained six pairs of items printed separately on six white $3 \times 5$ in. cards. The cards were arranged in a Cardex booklet so that each card could be presented separately by the $\mathrm{E}$. Six cards were also made which had only the stimulus member of each pair printed on them, and six additional cards had all six responses printed on them. The order of the stimulus cards was random with respect to the order of the cards containing tire stimulus-response pairs and, in addition, the arrangement of the six responses on the response cards was different for each trial.

\section{PROCEDURE}

The Ss were required to learn all the lists to a criterion of 1 errorless trial or until 24 unsuccessful trials had been completed. Each pair on the list appeared for $2 \mathrm{sec}$, then a blank card appeared for $2 \mathrm{sec}$. This, in turn, was followed by the next pair until all six pairs had been shown. Similarly, during the test trials, the stimulus member of each pair was presented for 2 sec, then the response card appeared for $2 \mathrm{sec}$; this was followed by a blank card and then the next stimulus card. The S's task was to recognize the correct response after the stimulus member of each pair was presented. The $S$ did this by pointing to the correct response on a card which contained all six possible responses. At the end of each list there was a 5-sec pause, and then the six pairs were repeated until the $S$ had learned all the correct responses. When the list was learned there was a 1-min pause, and then the second list was presented; when this, in turn, was learned, the procedure was repeated with the final list. At this time the $S$ had an opportunity to rest for $5 \mathrm{~min}$ before being asked to learn the next set of three lists. The same procedure was used in administering the second set of lists, except that for one set the $\mathrm{S}$ was required to make overt verbalizations during learning, while for the other set he was not.
The order of presentation of lists within a condition was counterbalanced according to a Latin-square design. In each group at least two Ss appeared in each of the six possible orders of presentation. For the deaf-oral and normal groups, the remaining $S$ s were assigned at random to one of the possible orders. Half the Ss in each group performed the verbalization condition first. The order in which the two sets of lists were presented remained constant.

\section{INSTRUCTIONS}

The instructions were given to each individual according to the method of communication which the $S$ normally used. That is, signs were used to communicate with the manual group, a combination of speech and gesture was used to communicate with the oral group, and speech was used to communicate with the normal group. All Ss were shown three practice lists consisting of two pairs of pictures, two pairs of words, and two pairs of syllables which were similar to those used in the main task. The $S$ was required to place his finger on the correct response after the stimulus member of the pair was presented. When the Ss demonstrated that they understood the task by completing all three practice lists correctly, the main task was begun. In one condition the Ss were told not to verbalize out loud or not to "sign," while in the other condition they were told to speak or "sign" the items as they appeared before them both in the acquisition and in the test trials. Observation of the Ss, behavior in the nonverbalization conditions indicated that the occurrence of overt verbalizations was very infrequent. RESULTS

Table 2 presents the mean number of trials to criterion for each group under each condition. A three-way analysis of variance for Groups by Conditions by Stimuli was performed (Winer, 1962, p. 328). This analysis indicated that the difference between the mean scores for the three stimuli was statistically significant $(F=38.28$, $\mathrm{df}=2 / 84, \mathrm{p}<.01)$. All other factors and combinations of factors were not significant. The mean scores for pictures, words, and syllables were $2.76,6.43$, and 8.66 , respectively, and a t test (Winer, 1962, p. 323) for the difference between each of these means indicated that each mean was significantly different from the other. The mean scores for the hearing, deaf-oral, and deaf-manual groups were $5.62,5.48$, and 6.76 respectively, and the analysis of variance indicated that there was no reliable difference between them $(p \leqslant .01)$.

An analysis of covariance for age effects indicated that the adjusted means for the three groups were not dependably different from each other $(\mathrm{p}<.01)$.

DISCUSSION
The results indicated that deafness did not affect the ability to learn the paired-associate lists. This is some what surprising in view of previous results (Pintner \& Paterson, 1917; Blair, 1957; and Hartman \& Elliott, 1965). In all of these studies the performance of the deaf was below that of hearing Ss. One difference between the early studies (Pintner \& Paterson, 1917; Blair, 1957) and the present experiment is that recall rather than recognition of items was studied. It may be that the deaf person's inability to engage in auditory imagery affects the mechanism of recall rather than the memory trace per se. This suggests that the model proposed for STM memory by Sperling (1963) and Conrad (1964), in which visual items are rehearsed in the auditory modality, holds only when recall is required of the Ss. Of course, Sperling's model deals with STM, and different mechanisms may be involved in a long-term memory or learning situation. But it is possible that recognition memory for visual items is primarily visual in nature. If this is so, it follows that the deaf, who have no apparent deficiency in visual memory, can perform at the same level as the hearing on memory and learning tasks which require recognition rather than recall. However, Hartman \& Elliott (1965) did use a form of recognition in their study of response alternation learning, and there were still differences between deaf and hearing Ss.

It is possible that auditory imagery is used by the hearing $S s$ even in recognition memory. But the auditory imagery which results from verbalization may not be a necessary component in the recognition process as it is in recall. Deaf Ss can transform the visual items into a kinesthetic modality in order to facilitate memory ability. This kinesthetic imagery may be efficient for recognition learning but not for recall learning. Unfortunately, the lack of difference 
in performance of the drat groups under the two verbalization conditions makes it difficult to assess the extent to which the deaf groups actually used articulatory (oral group) and kinesthetic (manual group) imagery in learning the material. However, the fact that overt rehearsal in the particular modalities used did not actually interfere with the learning process suggests that the overt rehearsal in the verbalization condition was, in fact, a manifestation of the covert rehearsal that took place in the nonverbalization condition. If, for example, the deaf $S$ s used only the visual system for coding and storage of information, the forced activity in an unrelated modality could be expected to disrupt learning. The fact that there was no disruption suggests indirectly that the modality used in overt rehearsal is, in fact, the modality ordinarily used during covert rehearsal. The lack of difference between the performances of the hearing group under the two verbalization conditions also supports the inference that the modality of rehearsal was the same under both conditions. This lack of difference between the verbalization conditions for all groups was, however, unexpected. According to Kurtz \& Hovland (1953) and Peterson \& Peterson (1959), overt rehearsal should lead to an improvement in performance, providing the presentation rate is slow. The 2 -sec intertrial interval used in this experiment is relatively slow, but apparently not slow enough to obtain an effect. It may be that overt responding actually inferfered with covert rehearsal, as suggested by Mackworth (1964) and Corballis (1965). This interference may have been sufficient to cancel the facilitatory effects normally associated with overt rehearsal, but not enough to actually cause a deficit in performance. Presentation rate is the critical variable, and experiments using different rates could provide the data to confirm or reject this explanation.
These fandings have some implications for the problem of linguistic deficiency in deaf children. It has been suggested by a number of investigators (Mykelbust, 1960; Conrad \& Rush, 1965; and MacDougall, 1969) that apart from the obvious effect which the lack of practice in speaking and hearing a language has, there is a more subtle reason for linguistic deficiency which is attributable to the effect of early deafness on more fundamental processes, such as memory and learning. The results of this study seem to suggest that at least the ability to associate, which must be an integral part of language learning, is not affected by deafness. This is supported by the finding that all groups performed similarly on the three lists involving different types of stimuli. Of special interest in this regard is the equivalence inability to learn nonsense syllables. These stimuli, as mentioned earlier, would be no more familiar to the hearing group than to the deaf groups, and, consequently, the ability to learn this particular type of material is a particularly good measure of the basic ability involved in this type of learning situation. Again, however, it should be pointed out that recognition memory was studied in this situation. Perhaps the ability to recall is more relevant to the production of language, and it may well be that the different type of imagery used by the deaf has an indirect effect on language learning through its effect on the process of recall. Studies are now under way to investigate this possibility.

\section{REFERENCES}

BLAIR, F. A study of the visual memory of deaf and hearing children. American Annals of the Deaf, $1957,102,224-263$.

CONRAD、 R. An association between memory errors and errors due to acoustic masking of speech. Nature, 1962, 193 . 1314-1315.

CONRAD, R. Acoustic confusions in immediate memory. British Journal of Psychology, 1964, 55, 75-84.

CONRAD, R., \& RUSH, $M$. On the nature of short-term memory encoding by the deaf. Journal of Speech \& Hearing Disorders, 1965, 30, 336-343.
CORBALLIS, M, C. Rehearsal and decay in short-term serial recall. Unpublished doctoral dissertation, McGill University, 1965.

HARTMAN, S \& ELLIOTT, L. L. Performance of deaf and hearing on a short-term memory task. Psychonomic Science, $1965,3,573-574$.

HENMON, V.. \& NELSON, M. Henmon-Nelson tests of mental ability. Teacher's manual. New York: Houghton-Mifflin, 1932 .

HINTZMAN, D. L. Classification and aural coding in short-term memory. Psychonomic Science, 1965, 3, 161-162.

KURTZ, K. H., \& HOVLAND, C. L. The effect of vocalization during observation of stimulus objects upon accuracy of recognition and recall. Journal of Experimental Psychology, 1953, 58, 193-198.

MacDOUGALL, J. C. Early auditory deprivation and visual behavior. Unpublished doctoral dissertation. McGill University, 1969.

MACKWORTH, J. F. Auditory short-term memory. Canadian Journal of Psychology, 1964, 18, 292-303.

MYKELBUST, H, R. The psychology of deafness. New York: Grune \& Stratton. 1960.

NOBLE, C. E Measurements of association value (a), rated associations $\left(a^{\prime}\right)$, and scaled meaningfulness $\left(\mathrm{m}^{\prime}\right)$ for the 2100 CVC combinations of the English alphabet. Psychological Reports, 1961, 8, 487-521.

PETERSON, L. R., \& PETERSON, M. J. Short-term retention of individual verbal items. Journal of Experimental Psychology, 1959, 58, 193-198.

PINTNER, R.. \& PATERSON, D. G. Learning tests with deaf children. Psychological Monographs, 1916, No. 20.

PINTNER, R., \& PATERSON, D G. A comparison of deaf and hearing children in visual memory for digits. Journal of Experimental Psychology, 1917, 2, 76-88.

SPERLING, G. A model for visual memory tasks. Human Factors, 1963, 5, 19-31.

THORNDIKE, E. L., \& LORGE, I. The teacher's word book of 30,000 words. New York: Bureau of Publications, Teacher's College, Columbia University, 1944.

WICKELGREN, W, A. Acoustic similarity and intrusion error in short-term memory. Journal of Experimental Psychology, 1965, 70, 102-108.

WICKELGREN, W. A. Auditory or articulatory coding in verbal short-term memory. Psychological Review, 1969, 76. 232-235.

WINER, B. J Statistical principles in experimental design. New York: McGraw-Hill, 1962. 